\title{
En mayúsculas y al rojo vivo: análisis semiótico-discursivo de la violencia homicida en la portada del periódico Q’hubo de Cartagena
}

\author{
Yennifer Martín Cabarcas ${ }^{1}$ \\ Sindy Rendón Mercado ${ }^{2}$ \\ Universidad de Cartagena
}

\section{Resumen}

La prensa tiene una importancia cada vez mayor a la hora de dar a conocer las distintas realidades que tienen lugar en las ciudades colombianas. Esta investigación realiza un análisis semiótico discursivo de la prensa sensacionalista en Cartagena, con el propósito de explicar cómo es representado el creciente fenómeno de la violencia urbana y sus implicaciones en lo que tiene que ver con las formas como los habitantes conocen, perciben e imaginan la ciudad. Recurriendo a los postulados de la semiótica discursiva, en particular a la Teoría Multimodal, se aborda la representación de la violencia homicida desde las categorías del Valor de la información y la Prominencia, usadas estratégicamente por quienes producen el periódico -en el caso del presente estudio, Q'hubo-, para construir un relato atractivo, capaz de atraer

\section{Abstract}

The press has an increasing importance when it comes to making known the realities that take place in Colombian cities. This research makes a discursive semiotic analysis of the gutter press in Cartagena, in order to explain how the growing phenomenon of urban violence is represented in it and understand the implications of this narrative, that have to do with the way people know, perceive and imagine the city. Drawing on the tenets of semiotics discursive, in particular the Multimodal Theory, addresses the representation of homicidal violence from the categories of Information Value and Prominence, used strategically by those who produce the paper -in the case of this study, Q'hubo- to build an attractive narrative, able to catch of the attention of readers. This

\footnotetext{
${ }^{1}$ Profesional en Lingüística y Literatura de la Universidad de Cartagena. e-mail: yennifer944@gmail.com

${ }^{2}$ Profesional en Lingüística y Literatura de la Universidad de Cartagena. e-mail: srm0120@hotmail.com
}

Recibido: Marzo, 2010 - Aprobado: Junio, 2010. 
la atención de los lectores. Esto es así porque los distintos modos de significar que confluyen en la portada actúan como marcadores discursivos que determinan y proporcionan formas de leerla.

Palabras clave: prensa sensacionalista, violencia homicida, multimodalidad, Valor de la información, Prominencia. is because the different semiotics modes that converge on the cover as a discourse act marker that identify and provide ways of reading it.

Key words: gutter press, homicidal violence, multimodality, Information Value, Prominence.

Cartagena de Indias fue considerada hasta los primeros años del presente siglo una de las ciudades más pacíficas del país, debido a que registró durante los momentos de más auge de la violencia en Colombia -esto es, durante las décadas de los ochenta y noventa-, índices de homicidio por debajo del promedio nacional. Mientras otras capitales como Medellín, Cali o Bogotá acaparaban la atención de las autoridades y de los medios debido al accionar de los grupos armados y las bandas delincuenciales al servicio del narcotráfico, La Heroica -como también se le conoce a Cartagena- era noticia, antes que nada, por su reconocimiento como patrimonio de la humanidad, por las cumbres de mandatarios, por los eventos del Concurso Nacional de Belleza o, cuando mucho, por los escándalos de corrupción de sus dirigentes.

Así las cosas, el relato dominante que representa a Cartagena durante buena parte del siglo XX está más asociado a su condición de principal destino turístico del país que a los hechos de violencia que tiñen de sangre distintas zonas rurales y urbanas de la geografía nacional. No obstante, esta realidad que presenta a Cartagena como una ciudad en cierta forma "tranquila" comienza a cambiar significativamente a partir de los primeros años del siglo XXI, cuando se presenta un incremento de los indicadores de inseguridad, sobre todo aquellos referidos a los delitos de mayor relevancia en los contextos urbanos: hurtos -principalmente en la modalidad del fleteo-, homicidios, secuestro y extorsión, siendo las tasas de homicidios las que registran el mayor aumento, especialmente bajo la modalidad del sicariato.

Según el Centro de Observación y Seguimiento del Delito (COSED) ${ }^{3}$, si bien las cifras presentan variaciones importantes (213 homicidios

\footnotetext{
${ }^{3}$ El Centro de Observación y Seguimiento de la Delincuencia Local es una entidad creada en el año 2006, y es la fuente distrital oficial y principal de recopilación estadística, estudio y análisis de información relacionada con la delincuencia y la violencia, siendo igualmente la fuente más importante de insumos para el diseño de políticas públicas locales que enfrentan el fenómeno de la delincuencia en el distrito de Cartagena.
} 
en 2007; 171 en 2008 y 243 en 2009), lo que marca una tendencia alarmante es el aumento de los casos de sicariato: de 44 homicidios en el año 2000 se pasa, por ejemplo, a 100 homicidios en el 2006 y a 149 en el 2009. Al decir de los analistas, es claro que aunque esta modalidad está asociada principalmente con el crimen organizado, como resultado de la rivalidad entre las bandas delincuenciales que operan en la región, es el resultado de la confluencia de diversos factores:

\begin{abstract}
Varios factores se han conjugado en un coctel molotov que tiene alborotados los centros urbanos: un posconflicto en medio de una desmovilización incompleta, el narcotráfico que está buscando que crezca el mercado interno de la droga, una justicia que no logra castigar ejemplarmente a los delincuentes, y la ausencia de una política criminal, todo ello en un contexto de iniquidad y pobreza que sirven de detonador para esta bomba de tiempo ("¿Qué pasa en las ciudades?", Semana, 23 de enero de 2010).
\end{abstract}

Al igual que en el resto del país, estos acontecimientos violentos son objeto de un cubrimiento especial en los diversos medios de comunicación, particularmente en la prensa hablada y escrita. Dentro de esta última, en la llamada crónica roja, que, fiel a su estética, ofrece una narración detallada con el propósito de atrapar al lector, y de paso asegurar un mercado que crece tanto o más que la propia cantidad de homicidios. Así, el relato del crimen se espectaculariza y llena de matices a la hora de comunicar los móviles, espacios, instrumentos, víctimas y victimarios de un crimen. ¿A quién asesinaron?, ¿quién lo hizo?, ¿qué arma utilizó?, ¿cómo se llevó a cabo el homicidio? son, entre otras, algunas de las preguntas que se desarrollan en las páginas principales.

No parece entonces casual que el nacimiento de este tipo de prensa sensacionalista vaya al compás, tanto en Cartagena como en el resto de los grandes centros urbanos del país, del repunte de la violencia homicida. En Cartagena, para referirnos al caso que nos ocupa, la aparición de Nuestro Diario en el año 2006 coincide, justamente, con el mayor índice de homicidios de la historia reciente de la ciudad. Este diario está adscrito a la casa editorial Editora del Mar, propietaria de El Universal, y posteriormente, en el año 2009, cambió su nombre por Q’hubo. Ante su éxito, a finales de 2010 entraron en circulación 
dos diarios sensacionalistas más, con características similares a las de Q’hubo: El Teso y Al Día .

De estos tres diarios, Q'hubo es el de mayor circulación: según indican fuentes del mismo periódico ${ }^{5}$, diariamente se venden cerca de 25 mil ejemplares, siendo los habitantes populares de la ciudad -conductores, comerciantes, vendedores informales, amas de casa, desempleados, etc.- sus principales destinatarios y lectores. Un primer análisis de $Q$ 'hubo revela la presencia de una estética singular en la narración del crimen, en la que usualmente la forma de presentar los acontecimientos resulta más llamativa que los mismos hechos y las características tipográficas en su conjunto interpelan sin disimulo alguno a los potenciales lectores.

Como en toda narración, Q'hubo presenta los hechos de sangre principalmente a través de la recreación de acciones, a menudo descritas bajo las formas de los verbos asesinar ("Asesinaron a un abogado") y matar ("Lo atracaron y lo mataron"), los cuales informan, de forma explícita, la alevosía y vileza que motiva la acción violenta. Por su parte, los actores involucrados en el hecho de sangre se presentan aludiendo a sus roles sociales, tal como se observa en los siguientes titulares: "Cayó compadre asesino", "Lo mató el sobrino". Finalmente, el espacio en el cual tiene lugar el suceso trágico aparece identificado con exactitud, de tal forma que puede ser reconocido por los lectores. Se trata, como se lee a diario, de un barrio o un sector de éste, una calle, una casa, una tienda o un establecimiento público...

Lo que convierte a $Q$ 'hubo en el periódico más vendido de la ciudad es, en resumidas cuentas, su estilo, que también se destaca por el uso de un léxico cotidiano y la configuración atractiva de la portada. Todos estos recursos están dirigidos a hacer que los lectores se sientan identificados con la situación narrada, y cobran forma en los titulares, bien sea en el uso de apodos: "El Bollo mató a Diofa"; de modismos o frases hechas: "Lo mató porque le mamó gallo", "Se quitó la rasquiñita" (las cursivas son nuestras); de títulos o frases de películas, canciones o novelas, cercanas a las prácticas cotidianas de los sujetos populares. Así, en lo que constituye la estrategia proxémica del periódico, se apela al habla y a las prácticas cotidianas de los lectores. Gracias a su relación con la oralidad y a sus formas de

\footnotetext{
${ }^{4}$ El primero pertenece a la casa editorial Editora del Mar y el segundo, a la casa editorial El Heraldo.

${ }^{5}$ Estas cifras corresponden al estudio realizado por el Estudio General de Medios (EGM) y la Asociación Colombiana de Investigación de Medios (ASIM) en las diecisiete ciudades más importantes del país durante el año 2009.
} 
narrar cercanas a la cotidianidad de los barrios, $Q^{\prime} h u b o$ se constituye como el espacio en el que el sujeto común y corriente se lee y se reconoce (Vélez et al., 1998).

Este trabajo pretende, entonces, realizar una descripción de estas estrategias discursivas tomando como punto de referencia las portadas de $Q^{\prime} h u b o$, con el propósito de producir un conocimiento sólido sobre los mecanismos discursivos utilizados por este tipo de prensa sensacionalista en la narración de los homicidios. Interesa explicar cómo se muestra esta realidad y cómo el lenguaje recrea, dramatiza o magnifica la violencia y la muerte, y así mismo, cómo estas representaciones influyen en la manera como los lectores se acercan a la realidad urbana. El análisis de la portada de $Q^{\prime} h u b o$, especialmente de las fotografías y titulares, nos permitirá evidenciar la forma en que el uso de cada modo semiótico conlleva distintos significados y valores que afectan la construcción del relato del crimen.

En este sentido, la selección de las unidades de análisis que constituyen el corpus de nuestra investigación se realizó tomando como criterio el incremento significativo de los índices de violencia en Cartagena (especialmente de homicidios): en los últimos tres años $(2008,2009,2010)$, de acuerdo con las cifras del COSED, el período con más índices de homicidios ha sido el segundo semestre del 2009, contabilizándose 130 asesinatos. Razón por la cual el marco temporal de análisis se centrará en tal período. Para el análisis de la información, hemos tomado como punto de partida los postulados teóricos de la Semiótica Discursiva, específicamente los referidos a la Teoría Multimodal, que propone un análisis descriptivo e interpretativo, enfocado en los discursos configurados por más de un modo semántico-discursivo (Kress \& van Leeuwen, 2006).

Desarrollaremos así dos categorías de análisis: Information value ("Valor de la información"), ya que acorde con la teoría multimodal los elementos en un espacio visual adquieren un valor según la ubicación que ocupen en dicho espacio, el cual también se halla dividido en partes con significaciones semánticas; y Salience ("Prominencia”), que alude al grado de atención que logra atraer un elemento gracias a su tamaño, ubicación, color, contraste e incluso la perspectiva. En esta etapa descriptiva, entenderemos por noticia $\mathrm{N}^{\circ} 1$ el recuadro informativo ubicado en el centro de la portada y cuya extensión suele ocupar la mayor parte de su espacio visual. Por noticia $\mathrm{N}^{\circ} 2$, el recuadro informativo ubicado, usualmente, en el extremo superior izquierdo de la portada; por noticia $\mathrm{N}^{\circ} 3$, el recuadro informativo cuya ubicación fluctúa entre el extremo 
superior derecho y el extremo inferior izquierdo de la portada. Por último, como noticia $\mathrm{N}^{\circ} 4$, el espacio informativo cuyo tamaño, en proporción con los demás recuadros, es menor, destacándose por no tener asignado un lugar específico de la portada, como se muestra en la siguiente ilustración:

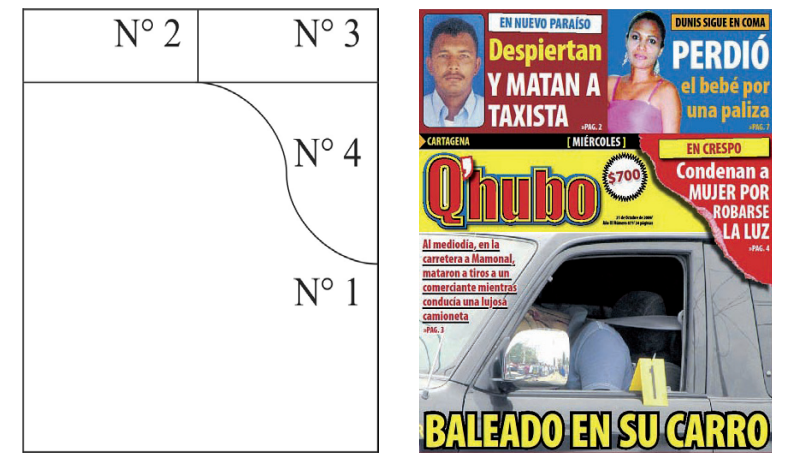

Imagen 1. Distribución de las noticias en la portada de $Q^{\prime} h u b o$

\section{Valor de la información: la muerte en primera plana}

Para mostrar cómo se realiza esta construcción de un imaginario de ciudad violento y trágico en las portada de $Q^{\prime} h u b o$, actualizamos, en el marco de la teoría multimodal, algunos de los preceptos teóricos de la Lingüística Sistémica Funcional (LSF). Como se sabe, ésta concibe el lenguaje como recurso para construir e interpretar significados en contextos sociales. La LSF estudia, desde una perspectiva sociosemiótica, la relación entre los elementos que se han seleccionado para construir un texto, y por lo tanto, analiza la forma cómo se construyen e interpretan los significados social y culturalmente en un contexto comunicativo determinado.

En esta teoría se apela a la concepción del carácter funcional del lenguaje de una manera más amplia, pues no sólo aborda su uso, sino la relación que se establece entre éste y el sistema lingüístico. De tal manera, en la LSF se tienen en cuenta tres funciones abstractas, denominadas metafunciones, a través de las cuales se expresa la dimensión funcional del lenguaje: función ideacional experiencial, según la cual el lenguaje se usa para representar nuestra experiencia con el mundo; función interpersonal, según la cual el lenguaje permite la interacción entre hablante y oyente, toda vez que a través del lenguaje se representan los roles sociales, la posición social de los participantes en la estructura social y su relación respecto a otros participantes; y función textual, observable en la forma en que se organizan los textos (coherencia y cohesión) (Ghio \& Fernández, 2008). 
A través de las anteriores metafunciones, el lenguaje se constituye como representación de la realidad, pues el sujeto no sólo se representa a sí mismo y a los demás con un papel social específico, sino que, además, construye su discurso como una reproducción del orden social al que pertenece. La LSF permite comprender las formas de significar de un sujeto por medio de las elecciones que realiza al momento de construir discursos. En la prensa, por ejemplo, se pueden observar estas formas de significar en los elementos que se utilizan para representar los sucesos y los participantes. Al mostrar cómo se describen los participantes, los procesos y las circunstancias, se sabe entonces cuál es la información que se quiere destacar en una noticia, cuáles son los aspectos que se consideran importantes y cuáles son los elementos que le indican al lector el grado de pertinencia de la información.

Todo esto permite comprender la importancia de la LSF para el análisis de las portadas de $Q^{\prime} h u b o$, con el propósito de dar cuenta sobre cómo las elecciones y selecciones semiótico-discursivas ayudan a configurar la carga simbólica de la información, al mismo tiempo que brindan al lector herramientas para la construcción de la imagen de quienes participan en ella. Teniendo en cuenta que el lenguaje va más allá de lo verbal, es preciso destacar que las imágenes que aparecen en las portadas de $Q^{\prime} h u b o$ tienen el mismo valor informativo que otras estructuras como los titulares o comentarios de las noticias. Por lo tanto, es acertado señalar que la portada de $Q^{\prime} h u b o$ puede ser leída como un texto configurado por diferentes códigos, en donde las imágenes y los titulares se funden hasta convertirla en un texto multimodal. Pero, ¿qué podemos entender por texto multimodal?

El conjunto de postulados teóricos de Gunther Kress y Theo van Leeuwen sobre cómo el texto se materializa en los modos de representación y comunicación da origen a la teoría multimodal, y a partir de ésta es posible acceder a "todos los modos de representación que entran en juego en el texto, con la misma exactitud de detalles y la misma precisión metodológica que es capaz de alcanzar el análisis del discurso con el texto lingüístico" (Pérez, 2007: 21). La teoría multimodal es útil para aproximarse a una perspectiva del lenguaje como una composición de modos semióticos que va más allá de lo verbal: los sonidos, los gestos, las imágenes, etc. Mediante estos aportes teóricos es posible conocer que los distintos modos semióticos facilitan la construcción o materialización del lenguaje, pues son producidos con cargas de valor cultural, social e histórico que conducen a crear representaciones de una realidad específica. En consecuencia, un texto es multimodal cuando está configurado por un conjunto de modos semióticos con capacidades y limitaciones 
específicas, y producidas culturalmente, otorgándole la facultad de significar y comunicar. Además, un texto multimodal es coherente en sí mismo y en él están inmersas estructuras de poder, ya que la producción y utilización de los distintos modos, signos y combinaciones específicas están determinadas por los intereses del productor de dicho texto. Considerar la portada de $Q^{\prime} h u b o$ como un texto multimodal permite, por lo tanto, un análisis desde las categorías propuestas por la teoría multimodal. Entre estas categorías, cabe destacar la prominencia, que nos permite reconocer qué elementos en la portada guardan un mayor valor, teniendo en cuenta su tamaño, color, brillo y colocación con respecto a los demás componentes de la misma.

De acuerdo con lo anterior, si el valor informacional de los distintos modos de un espacio visual es proporcional a su ubicación, color o tamaño, es válido entonces afirmar que en $Q$ 'hubo cada recuadro específico debe su ubicación a los intereses del periódico. Es decir, la ubicación de la noticia en el centro de la portada no es un hecho fortuito, sino una herramienta discursiva con la cual se pretende dar un significado preciso a la información. De esta forma, el valor de los distintos elementos de la portada de $Q^{\prime} h u b o$ está determinado por la manera en que es configurada: en ella las noticias poseen una carga semántica específica establecida por distintos elementos que la hacen prominente, como es el caso de la ubicación. Es así como la portada de Q'hubo puede concebirse como un modo semiótico donde la información está organizada de tal manera que existe un claro intercambio comunicativo entre el periódico y el lector. De allí que los diferentes espacios visuales tengan valores semánticos diferentes.

A la hora de organizar el mensaje, la calidad de la noticia, la continuidad y la capacidad de recuperar la información cumplen un papel fundamental (Ghio \& Fernández, 2008: 92). Esto lleva a concluir que la información en un mensaje se organiza sobre dos sistemas: el temático (Tema/ Rema) y el sistema de jerarquización (Dado/ Nuevo). Tal es el caso de $Q^{\prime} H u b o$, donde la ubicación de un espacio visual dentro de la portada está determinada por la carga semántica. En otras palabras, el espacio visual que ocupa una noticia da cuenta del valor informacional que el periódico le atribuye al hecho narrado. Por ello, cuando una noticia ocupa la mayor parte del espacio visual de la portada, y además se ubica en el centro, es porque existe un sistema jerárquico de información cuyas herramientas discursivas (ubicación, color, tamaño) obligan al lector a dirigir la mirada a las noticias que ocupan un lugar predominante. 
Así, en la portada de $Q^{\prime} h u b o$ es la noticia $\mathrm{N}^{\circ} 1$ el espacio visual con mayor valor semántico. Dado el perfil del periódico, los hechos narrados en este recuadro retratan una ciudad violenta e insegura que se había acostumbrado, quizá hasta la aparición de este periódico, a una representación de tarjeta postal, apacible y plácida. El análisis minucioso de las portadas revela que el eje temático sobre el cual giran las noticias es la violencia homicida que vive la ciudad que la convierte ya no en el lugar mágico y de ensueño promocionado por las agencias turísticas, sino en un lugar trágico donde los hechos de sangre se han convertido en parte de la cotidianidad de sus habitantes. Q'hubo destaca, desde una lógica sensacionalista, la sevicia, la vileza y la intransigencia de una ciudad, recurriendo a complejas herramientas discursivas que apelan a las expectativas, las representaciones y los modelos de realidad que supuestamente esperan encontrar los lectores. De esta forma, quienes lo producen justifican el tipo de cubrimiento: así es la realidad y esto es lo que la gente quiere ver.

Cuando vemos el periódico se observa con claridad que el espacio visual de la noticia es destacado mediante títulos cuyas dimensiones oscilan entre 100 y 194 puntos tipográficos. Proporcional a esto, el recuadro $\mathrm{N}^{\circ} 1$ logra absorber la mirada del lector utilizando el color amarillo (en el 60\% de los portadas analizadas) contrastado con el negro, blanco y rojo (Ver Gráfico 1). Estas tonalidades comunican al lector diversas emociones y evocan sensaciones de agresividad, indignación, temor, entre otras. No obstante, gracias a la efectividad de los recursos empleados, el lector termina apropiándose de esta representación de ciudad, que por lo reducida y espectacular, es tan sesgada e incompleta como la representación que construye el discurso turístico (Cf. Ávila, 2008).

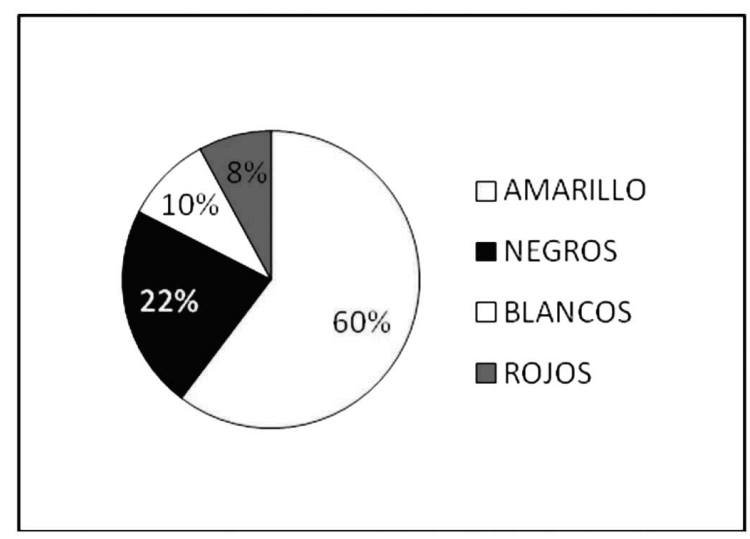

Grafico 1. Colores utilizados en los titulares de la noticia $\mathrm{N}^{\circ} 1$ 
Como podemos comprobar, los titulares dan forma al carácter sensacionalista del periódico. Su hipertrofiada tipografía y la paleta de colores que utilizan prueban el tratamiento espectacularizado que se hace del crimen y de las tragedias ocurridas a los habitantes de la ciudad, más allá de que algunos de ellos se encuentren por fuera de la legalidad. En $Q ' h u b o$, al igual que en El Teso y Al Día, el relato del crimen es la rentable mercancía que se vende a los sectores populares bajo el pretexto - ¿prejuicio?- de que es el relato que quieren leer. Un atento examen de los recuadros informativos de la noticia $\mathrm{N}^{\circ} 1$ comprueba, así mismo, que la muerte vende (tal como lo ilustran las portadas analizadas del $6,8,10,12$ y 22 de octubre del año 2009. Todas ellas son encabezadas por titulares con grandes letras amarillas bordeadas de color negro: "Lo lincharon", "Lo asesinaron llamando a su mamá", "Lo mataron delante de su familia", "Los mató en la cama”, "Matan a abogado y a estudiante".

Del mismo modo, el uso de estos titulares resulta muy eficaz por la aparición de verbos como "matar" o "asesinar", que en formas como: “iLo mataron!”, llevan al lector a preguntarse: ¿a quién?, ¿quién lo hizo?, ¿por qué? Nótese que la forma pronominal "lo", comúnmente utilizada, juega a favor del morbo: siembra en el lector la curiosidad y necesidad de obtener más información sobre el tema que relata la noticia, le incita a descubrir, al interior de las páginas, todos aquellos detalles que el "lo" impersonal del titular le oculta. Los titulares, sin embargo, no son ni la única ni la herramienta principal para desarrollar este tipo de relato, pues en Q'hubo tal responsabilidad descansa principalmente en la imagen. De hecho, mediante el número de fotografías que aparecen en el recuadro y la forma como son presentadas, se determina la importancia de una noticia en el espacio visual de la portada. En consecuencia, luego de analizar cuidadosamente las portadas escogidas para el análisis, se concluye que la noticia $\mathrm{N}^{\circ} 1$ posee un valor simbólico agregado en relación con las demás noticias que aparecen en las portadas.

Así se verifica, al comparar (ver Anexo) el recuadro informativo de dicha noticia con los recuadros informativos de las noticias 2, 3, y 4. Pues la noticia $\mathrm{N}^{\circ} 1$ es la única en cuyo fondo aparece, por lo general, una fotografía. Por el contrario, las demás noticias nunca llevan como fondo de sus recuadros una fotografía. Además, cabe resaltar que en el $44 \%$ de las noticias $\mathrm{N}^{\circ} 1$ aparece más de una fotografía (como se observa en el gráfico 2). Por su parte, en los recuadros informativos de las noticias 2, 3 y 4 sólo aparece una fotografía, y en algunos casos, ninguna. 


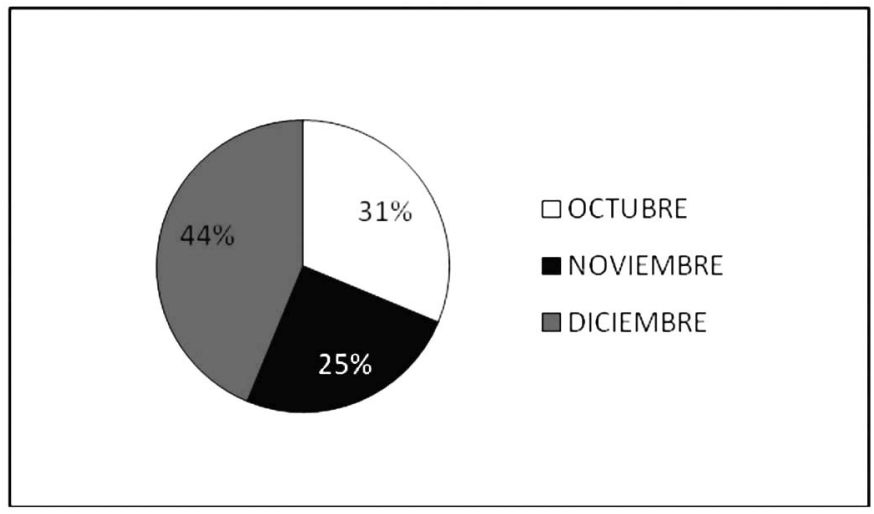

Gráfico 2. Noticias $\mathrm{N}^{\circ} 1$ en las que aparece más de una fotografía.

Esta comparación demuestra que, en relación con las otras noticias, el espacio visual $\mathrm{N}^{\circ} 1$, además de contar con una ubicación privilegiada, es el más elaborado de la portada: los colores han sido seleccionados concienzudamente y los contenidos redactados de tal modo que logren más cercanía con el lector. Por último, en este recuadro las imágenes atrapan al lector mostrándole un mundo violento que no le es ajeno. Debemos anotar, igualmente, que la caracterización de lo que es Nuevo o Dado depende del grado de importancia o prominencia de la noticia. Entre las distintas noticias de una portada, por ejemplo, lo Nuevo correspondería al hecho más novedoso según el criterio del redactor del periódico o a aquello que causa extrañeza. En sintonía con estos postulados, en la portada de $Q$ 'hubo se organiza la información desde lo Nuevo (aquello que causa impacto), hasta la información con menos importancia (la cual corresponde a lo Dado).

La ubicación de lo Nuevo y lo Dado depende de las características de las noticias y del grado de espectacularización que presentan los hecchos. Este grado de espectacularización depende, a su vez, de la cantidad de personas implicadas y la maldad que caracterice a los crímenes, así como del número de noticas en la portada. Es por esto que, aunque en las noticias $\mathrm{N}^{\circ} 3$ y $\mathrm{N}^{\circ} 4$ también se relaten asesinatos, los hechos no despiertan el mismo grado de morbo de las noticias $\mathrm{N}^{\circ} 1$. En los recuadros $\mathrm{N}^{\circ} 3$ y $\mathrm{N}^{\circ} 4$ también se tratan otros temas relacionados con la farándula y los deportes, aún así, las noticias que más se observan son las que corresponden a temas judiciales, los cuales remiten a noticias divulgadas con anterioridad en el periódico. Esto es, de datos o información nueva con respecto a la captura de delincuentes. Si en $Q^{\prime} h u b o$ lo nuevo está dado por la novedad, es decir, por el grado de extrañeza que provocan los hechos presentados, la organización jerárquica de la portada indica que las noticias judiciales, o de otra 
índole, corresponden a lo Dado en comparación con los asesinatos (de ahí su ubicación en el extremo derecho de la portada). Cabe destacar, por supuesto, que esto no es una caracterización definitiva para todas las portadas analizadas. Kress \& van Leeuwen (2006) afirman que la caracterización de lo Dado y lo Nuevo está dada por el criterio del emisor, por lo que éste considere como nuevo o importante:

[...] This shows how the Given-New structure can be ideological even in diagrams. If the horizontal order of the communication model were rearranged in a similar way $[\cdots]$ it would no longer depict communication from the point of view of the "sender", with the "receiver" as New, and problematic (Will the message "hit the target"? Will it have the attended effects?). Instead, the "reader" would become the origin and departure of the communication process, and the "sender" ('author') problematic, as has indeed happened, for instance, in literary reception theory $(184)^{6}$.

\section{Prominencia: en mayúsculas y al rojo}

\subsection{El tamaño: sensacionalismo en puntos tipográficos}

Los titulares son el "[...] encabezamiento destacado, que suelen tener los materiales de lectura de los periódicos y revistas" (Rojas, 2003: 13); su función principal es atraer la atención del lector e incitar la lectura. Si en la portada de $Q^{\prime} h u b o$ se confronta el tamaño de los titulares con la noticia a la que pertenecen, se advierte que, además de los colores brillantes y luminosos, su tamaño también guarda relación con la importancia atribuida a la noticia que anuncian, es decir, se ajustan a la perfección al espacio visual al que pertenecen, y sobretodo, a la relevancia del hecho noticioso.

En las portadas analizadas destacan, por su tamaño, los titulares pertenecientes al espacio visual de la noticia $\mathrm{N}^{\circ} 1$ que, como se sabe, ocupa en orden de jerarquía el centro de la portada. Estos titulares, rellenados de amarillo, negro o rojo, son los encargados de establecer el contacto visual con el lector y proponerle desconcertantes

\footnotetext{
6 “[...] Esto muestra cómo la estructura Dado-Nuevo puede ser ideológica, incluso en los diagramas. Si el orden horizontal del modelo de comunicación fuera reordenado de manera similar [...] ya no representaría la comunicación desde el punto de vista del "emisor", con el "receptor" como Nuevo, y problemático (¿Habría el mensaje de cumplido su cometido? ¿Tendría este los efectos deseados?). Por el contrario, "lector" se convertiría en el origen y la partida del proceso de comunicación, y el "emisor" ("autor") problemático, como ha sucedido, por ejemplo, en la teoría de la recepción literaria" (La traducción es nuestra).
} 
situaciones a las que tiene acceso una vez adquiere el periódico. Usualmente, la noticia principal ocupa gran parte de la extensión de la portada, lo que hace posible un tamaño de letra o medida grande cuyos valores oscilan entre 100 y 194 puntos tipográficos. Para hablar del tamaño tipográfico es necesario tener en cuenta que la noticia principal generalmente está asociada a algún tipo de hecho violento y/o anormal que rompe con el orden pacífico de la vida diaria de los cartageneros. De allí que el $62 \%$ de los titulares de la noticia $\mathrm{N}^{\circ} 1$ esté redactado en 100 o en más puntos tipográficos.

Esta evidencia permite afirmar que en Q'hubo el tamaño es proporcional al grado de escándalo e impacto que se pretende causar en el lector-espectador. Para Kress \& van Leeuwen (2006), el tamaño es un factor que permite determinar cuán prominente es un elemento dentro de un espacio visual, y por lo tanto, el valor informativo que tiene. En este sentido, es claro que los titulares de $Q^{\prime} h u b o$ actúan como poderosas estructuras discursivas diseñadas para enganchar al lector, no sólo en virtud de sus colores brillantes y atrayentes, sino de su proporción. Por ello, se imponen en el espacio visual de la portada, magnificando los acontecimientos violentos.

El tamaño de los titulares en $Q$ 'hubo, entonces, es una pieza fundamental en la portada del periódico. Facilita, en lo que se puede considerar su función fática, la relación comunicativa con el lector, su atención. Sólo en el recuadro de la noticia $\mathrm{N}^{\circ} 1$ se constata que el $62 \%$ de los titulares analizados está redactado en un tipo de letra que oscila entre los 100 y los 194 puntos tipográficos (Ver Gráfico 3). Aunque por lo general la noticia $\mathrm{N}^{\circ} 1$ se ubica en el centro de la portada, en algunas ocasiones se extiende desde el centro hasta la franja inferior, donde usualmente se ubican las noticias $\mathrm{N}^{\circ} 3$ y $\mathrm{N}^{\circ} 4$. Esta ubicación permite la utilización de títulos de grandes dimensiones, logrando así un mayor realce de las noticias que desarrollan sucesos violentos.

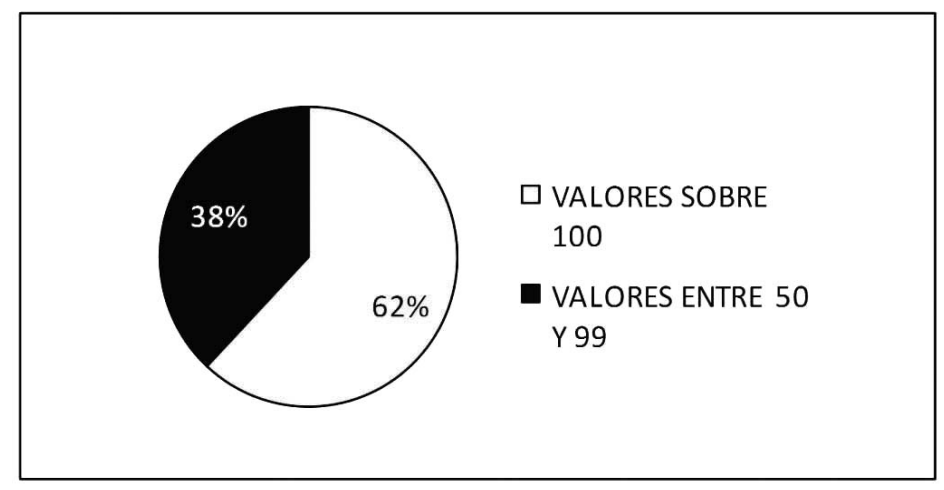

Gráfico 3. Tamaños de letra en la noticia $\mathrm{N}^{\circ} 1$ 
Por el contrario, el tamaño de letra de los titulares en las noticias vecinas es inferior a 100 puntos tipográficos. Apelando nuevamente a los postulados de la Teoría Multimodal (Kress \& van Leeuwen: 2006), reafirmamos, por lo tanto, la conclusión de que el gran tamaño de los titulares sugiere la manera correcta de leer un mensaje o el lugar específico a la que el lector debe dirigir su mirada. Como afirma Rojas: "Los titulares se caracterizan por su condición informativa, por su redacción, por llamar la atención, la extensión del título demuestran la importancia de la noticia y sus dimensiones y deben poseer legibilidad" (2003: 37). A partir de esto, es válido afirmar que en $Q^{\prime} h u b o$ existe una jerarquía de información que, entre otras características, está determinada por el tamaño de los puntos tipográficos de los titulares.

El caso de la noticia $\mathrm{N}^{\circ} 2$ reafirma esta hipótesis pues, aunque también muestra hechos violentos y criminales como homicidios y robos, el tamaño de letra utilizado es inferior: el 70\% de los titulares de este recuadro informativo está redactado en un tamaño de letra inferior a los 100 puntos tipográficos, oscilando entre los 30 y los 60 puntos. El uso de un tamaño de letra pequeño evidencia, de esta forma, que el valor informativo de tales noticias es inferior al de la noticia $\mathrm{N}^{\circ}$ 1 , puesto que, si bien los hechos del recuadro $\mathrm{N}^{\circ} 2$ también aluden a noticias relacionadas con la muerte, los hechos allí presentados están subordinados con respecto al grado de asombro o impresión que producen los hechos de la noticia $\mathrm{N}^{\circ} 1$ en el lector.

La comparación de los hechos registrados en las noticias $\mathrm{N}^{\circ} 1$ y $\mathrm{N}^{\circ} 2$ evidencia que la información de la noticia $\mathrm{N}^{\circ} 1$ predomina gracias al valor del contenido que presenta, el cual está determinado (como se mencionó) por la alevosía, premeditación, sevicia de los crímenes y su nivel de impacto en los habitantes de la ciudad. De esta forma, los sucesos de la noticia $\mathrm{N}^{\circ} 2$ se perciben como menos impresionantes o cercanos a los habitantes de Cartagena. Tal es el caso de las noticia $\mathrm{N}^{\circ} 2$ del ejemplar del 10 de octubre de 2009. En éste el titular de la noticia es: "En Turbana. Balearon a operario del acueducto", mientras el titular de la noticia $\mathrm{N}^{\circ} 1$ informa: "En Villa Hermosa. Asesinado delante de su familia". En la notica $\mathrm{N}^{\circ} 2$ se utiliza un tamaño de letra inferior, pues ella registra información de un suceso (asesinato) ocurrido en un lugar, un municipio, apartado de la ciudad. Por el contrario, la noticia $\mathrm{N}^{\circ} 1$ informa sobre un homicidio ocurrido en la ciudad y que, en cuanto también presenta claros signos de crueldad y sevicia, permite una mayor espectacularización. El tamaño grande de la letra es, justamente, uno de sus recursos. 
Adicionalmente, el titular de la noticia $\mathrm{N}^{\circ} 1$ logra mantener la atención sobre el hecho violento que comunica gracias al apoyo del antetítulo y el sumario que suelen acompañarlo. Estos últimos están redactados en 30 y 24 puntos, respectivamente. Cabe destacar que de estas partes del titular sólo es posible ubicar el antetítulo en algunos recuadros de las noticias $\mathrm{N}^{\circ} 2,3, \mathrm{y}$ 4. Ello permite anotar que estos recuadros difieren significativamente en tamaño en comparación con el recuadro de la noticia $\mathrm{N}^{\circ} 1$-sus titulares tienden a ser inferiores a los 60 puntos tipográficos-, y que la información que comunican no es tan relevante. En ese sentido, el tamaño de letra se convierte en un factor relevante en la portada de $Q^{\prime} h u b o$ : por medio de él se resaltan expresiones, palabras o cifras.

En las noticias $\mathrm{N}^{\circ} 3$ el tamaño de la letra oscila entre los 25 y 110 puntos, mientras que la noticia $\mathrm{N}^{\circ} 4$ es redactada entre los $20 \mathrm{y}$ 59 puntos tipográficos. En $Q^{\prime} H u b o$ el tamaño de letra a menudo se utiliza para resaltar ciertas palabras, como lo ilustran los siguientes casos: "En menos de 24 horas mataron a tres", "Murió operario de acueducto", "Perdió el bebé por una paliza", "Volqueta mata a vigilante" (Las cursivas son nuestras). En estos titulares las palabras resaltadas presentan un tamaño de letra claramente mayor: en el primero de ellos, por ejemplo, las palabras resaltadas tienen un tamaño de letra de 75 y 110 puntos tipográficos, respectivamente, que sobresale entre los valores utilizados generalmente en las noticias 3 y 4 . Nótese que las unidades: "mataron a tres", "murió", "perdió", "mata”, que exhiben un tamaño superior, están relacionadas con contenidos de muerte y violencia.

En consecuencia, el tamaño diferencial de la letra en las noticias $\mathrm{N}^{\circ} 3$ y $\mathrm{N}^{\circ} 4$ también es una forma de llamar la atención, pese a que estas noticias ocupan un espacio reducido en la portada en comparación con la noticia $\mathrm{N}^{\circ} 1$. Estas variaciones en el tamaño de letra permiten focalizar la mirada del lector y dirigirla hacia ciertas palabras cuyo significado está cargado de connotaciones referidas a al crimen y que, por lo mismo, tienen la fuerza necesaria para crear puntos de atención y asegurar la lectura del relato. Así como el recuadro condiciona el tamaño de letra de la noticia -recuérdese que en el $62 \%$ de las portadas analizadas el tamaño de letra en las noticias $\mathrm{N}^{\circ}$ 1 oscila entre los 100 y 194 puntos tipográficos-, también es cierto que el contenido de la noticia es el que determina el tamaño que ésta ocupa en la portada. En la noticia $\mathrm{N}^{\circ} 1$, que reporta hechos de sangre, 47 de las 72 portadas analizadas tematizan asesinatos. Este número corresponde al $65 \%$ de los ejemplares, como se puede observar en el gráfico $\mathrm{N}^{\circ} 4$. 
De esta forma, el tamaño del recuadro en las noticias $\mathrm{N}^{\circ} 3$ y $\mathrm{N}^{\circ} 4$ está determinado por el número de noticias que se presentan y la distribución que éstas tienen en la portada, donde la noticia $\mathrm{N}^{\circ} 1$ es la que ocupa el mayor espacio. En portadas como: "Abusó de sus hijos pero su mujer lo perdonó", "Volqueta mata a vigilante", "Asesinan a uno en Los Caracoles y a otro (foto) en el 20 de Julio", "Ataque con piedras deja menor herida", "14 años de cárcel por extorsionista", se evidencia que el elemento predominante son los hechos criminales, la violencia y la muerte, ya sea accidental o infringida. Aunque también se muestran otros hechos relacionados con el deporte y la farándula, como se puede observar en las portadas de noviembre donde se presentan las noticias sobre el Reinado de Independencia y el Concurso Nacional de Belleza: "Hoy gran desfile de independencia", "Los chismes de la noche de coronación", "Real Cartagena visita al Junior", etc.

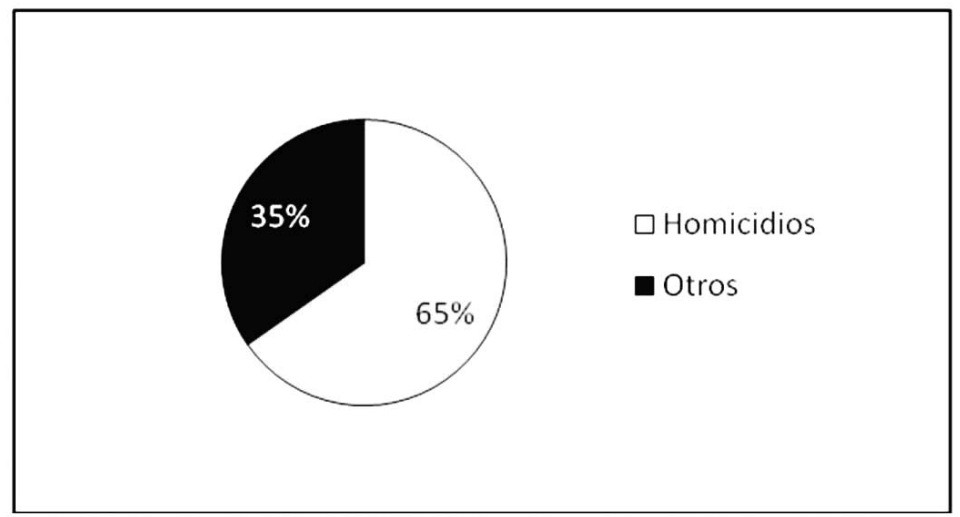

Gráfico 4. Porcentaje de los contenidos temáticos de la noticia $\mathrm{N}^{\circ} 1$

Para concluir, se puede decir que aunque el tamaño del recuadro de las noticias $\mathrm{N}^{\circ} 3$ y $\mathrm{N}^{\circ} 4$ reduce de cierta forma la atención del lector hacia los hechos que éstas relatan, la forma en que los hechos se presentan -registro coloquial, juegos tipográficos y de colorcontribuyen a captar su interés, que al final de cuentas es lo que lo que pretende Q'hubo.

\subsection{El color: la muerte no sólo se viste de negro}

La presencia de colores vivos en la portada de $Q^{\prime} h u b o$ es otra de sus características. Los colores vivos son útiles de cara al propósito de llamar la atención del lector y organizar y clasificar la información. Su análisis, por tanto, permite un acercamiento a otro de los recursos 
que expresan la ponderación en el periódico y que más permiten entender la estética de la crónica roja en el relato de los homicidios. Así, el análisis de las portadas seleccionadas evidencia que el $60 \%$ de los titulares de la noticias $\mathrm{N}^{\circ} 1$ se redactó con relleno de color amarillo, un $22 \%$ con color negro, un $10 \%$ con color blanco, y en último lugar, un $8 \%$ con color rojo (Ver Gráfico 1).

Teniendo en cuenta la información que proporciona este gráfico, cabe destacar que cada color tiene su propio significado y está asociado a sensaciones o emociones en razón de las "experiencias universales profundamente enraizadas desde la infancia en nuestro lenguaje y nuestro pensamiento" (Eva Heller, 2004, citado por Olga Carreras, 2008). Es decir, la representación y el efecto que tienen los colores es resultado de complejas construcciones simbólicas relacionadas con la tradición histórica. Por lo mismo, para Kress \& van Leeuwen (2006), el color es un modo semiótico que, además de poseer funciones comunicativas, permite representar, proyectar y construir relaciones sociales. Veamos:

In all these cases colour represents, projets, enables or constructs social relations -it is interpersonal. It is not just the case that colours "expresses" or "means" things such as "calm" or "energy"; rather people actually use colour to try to energize or calm down other people. Putting it more generally, color is used to act on others, to send managerial messages to workers. Or parental messages to children, as we have shown in an analysis of a child's room (Kress \& van Leeuwen, 2006: 230) ${ }^{7}$.

Antes de producir un efecto de calma, tristeza o miedo en el lector, el color de un objeto debe llamar su atención: una vez se logra la relación comunicativa con este modo semiótico es posible descifrar el mensaje que el emisor pretendió transmitir. Pero, ¿qué pretenden transmitir los redactores de $Q^{\prime} h u b o$ al utilizar, con insistencia, el color amarillo para el relleno de los titulares principales? La respuesta a esta pregunta viene de algunos autores que consideran que si bien el amarillo es un color asociado a la luz o a la alegría, al combinarse

\footnotetext{
7 "En todos estos casos el color representa, proyecta, activa o construye las relaciones sociales -es interpersonal-. No es sólo el caso de que los colores "expresan" o "significan" cosas como "calma" o "energía", sino que la gente realmente usa el color para tratar de dinamizar o tranquilizar a otras personas. Poniéndolo de manera más general, el color se utiliza para actuar en los demás, para enviar mensajes gerenciales a los trabajadores. 0 mensajes de los padres a los niños, como hemos demostrado en un análisis de la habitación de un niño" (Kress \& van Leeuwen, 2006: 230). (La traducción es nuestra).
} 
con el color negro -cosa que ocurre en el periódico-, automáticamente se convierte en un tono intenso, violento y agudo. De esta forma, pierde su carácter alegre asociado a la felicidad y a la naturaleza (Zelanski: 2001). Es lo que sucede justamente con la noticia $\mathrm{N}^{\circ} 1$, recuadro informativo que, como se ha apuntado, desarrolla contenidos relacionados con hechos violentos: homicidios, riñas, robos, etc. El uso del color amarillo en este recuadro difiere de lo que sucede en otras noticias, en la medida que los titulares amarillos siempre se presentan con contorno negro, color asociado con el misterio, el miedo y la muerte.

En este sentido, el color utilizado para el relleno de los titulares causa una reacción emocional en el lector (Kress \& van Leeuwen, 2006). La presencia del color amarillo en las noticias $N^{\circ} 1$, acompañado del negro, reafirma su carácter violento y el interés de alarmar y escandalizar al lector. El color en la portada de $Q^{\prime} h u b o$ actúa, entonces, como un modo semiótico discursivo capaz de crear y representar la información de una realidad determinada. De esta forma es como el color permite la realización de lo que Halliday (1973, citado por Ghio \& Fernández, 2008: 23) denominó las “metafunciones del lenguaje”.

Así también lo conciben Kress \& van Leeuwen (2006), toda vez que hablan del color como un modo semiótico integral, cuyas cualidades le permiten poner en escena la función ideacional, que se evidencia al crear y construir representaciones del mundo; la función interpersonal, que ayuda o posibilita las interacciones sociales que se caracterizan por tener propósitos y relaciones sociales especificas; y la función textual, que permite construir y organizar las representaciones del mundo y las interacciones sociales en textos cohesivos y coherentes. El color en la portada de $Q$ 'hubo actúa como un modo semiótico discursivo que permite la puesta en escena de estas metafunciones, por cuanto el color amarillo con el que se presentan los titulares resalta e intensifica el hecho que anuncia, le da preponderancia, permitiendo a los lectores construir una idea sobre los acontecimientos que tuvieron lugar.

Con el uso del color amarillo se crea una representación de la realidad y se muestra cuán alarmante puede ser un suceso, sobre todo si le atribuyen significados de violencia. De la misma manera, cuando se utiliza el negro como relleno de letra en un titular que narra un crimen atroz se representa una realidad fúnebre, violenta y cruel. En la misma línea, atendiendo a la idea de que en la función interpersonal se da una relación de intercambio entre los participantes (emisorreceptor), el color también puede calificarse como un modo semiótico capaz de establecer relaciones de intercambio comunicativo, pues es 
capaz de causar un efecto en el receptor: hacer que éste se sienta o actúe de una forma específica. En palabras de Kress \& van Leeuwen, el color "is also used to convey 'interpersonal meaning': it allows us to realize 'colours acts'(as language permits 'speech acts'). It can be and is used to do things to or for each other [...]" (2006: 229) ${ }^{8}$.

En este sentido, se puede afirmar que el color utilizado en $Q^{\prime} h u b o$ para el relleno de los titulares comunica unos significados específicos que impactan emocionalmente al lector, mientras que el color amarillo de las noticias $\mathrm{N}^{\circ} 1$ reafirma el carácter violento de la información, y el color negro, bien sea que aparezca en los titulares o en el fondo, transmite sensaciones de tristeza, miedo y angustia con las que el lector suele identificarse. Esta tendencia de trasmitir emocióninformación se evidencia al mismo tiempo en los colores del relleno de los textos, donde el amarillo es el color dominante por razones ya mencionadas. La función del color en el titular no se remite a lo ornamental: en los titulares de la noticia $\mathrm{N}^{\circ} 1$ el color amarillo, de la misma manera que atrae la mirada gracias su efecto luminoso, sugiere apreciaciones, e incluso, proporciona y complementa la información que pretende trasmitir el contenido del texto.

La forma como están elaborados los titulares de Q'hubo no sólo proporciona información sobre un hecho determinado, sino que, además, posibilita una relación más próxima con los lectores, que se ve reforzada con el empleo de un lenguaje coloquial. Por ello, los titulares, más allá brindar información precisa y objetiva sobre un suceso, comunican (mediante adjetivos calificativos: "Monstruoso", "Cruel" “Intolerante!”) emociones y juicios sobre el hecho noticioso. Se trata de apelar a la sensibilidad (pathos) del lector, quien por lo general termina escandalizado, aterrorizado o con ansiedad con sólo haber leído el sugestivo y colorido titular.

En cuanto a los titulares de $\mathrm{N}^{\circ} 2$ (Ver Gráfico 5), se observa que el color más utilizado es el blanco, caracterizado por poseer más luminosidad (según la teoría del color de Goethe). El blanco, además, tiene la facultad de resaltar cualquier otro color con el que se combine. Así mismo, es un color que brinda un significado positivo al contenido que presenta. Si se tiene en cuenta que el color amarillo es el más usado en las noticias $\mathrm{N}^{\circ} 1$, y que el uso de este color en exceso suele tener un efecto perturbador, es lógico que el blanco sea el segundo

8 “También se utiliza para transmitir 'el significado interpersonal': nos permite realizar 'actos de colores' (como el lenguaje permite los 'actos de habla'). Se puede y se utiliza para hacer cosas al o para el otro. [...]" (2006: 229). (La traducción es nuestra). 
color más usado en la portada de $Q^{\prime} h u b o$ : le brinda estabilidad y equilibrio, frente a un color tan alarmante como el amarillo.

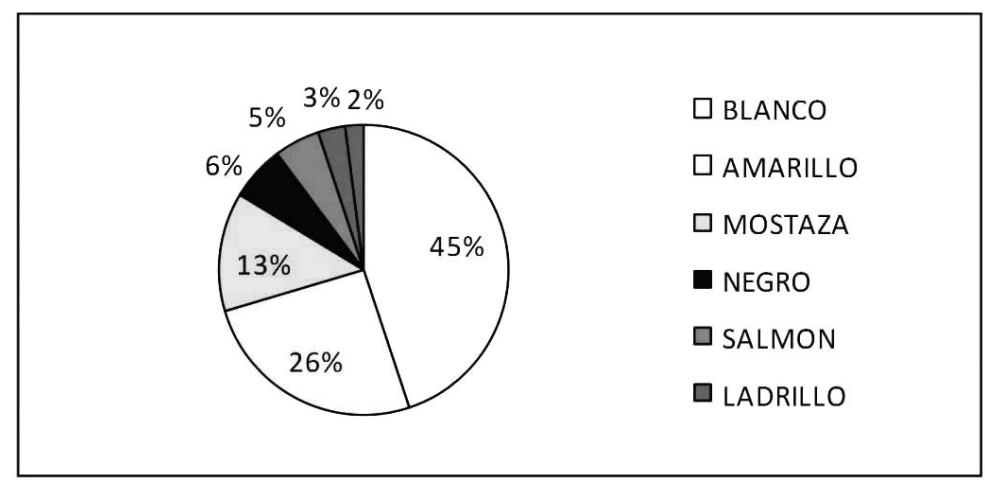

Gráfico 5. Colores utilizados en los titulares de la noticia $\mathrm{N}^{\circ} 2$

El uso complementario del blanco y el amarillo se identifica en las noticias $\mathrm{N}^{\circ} 3 \mathrm{y} \mathrm{N}^{\circ} 4$, ya que estos son los colores de letra más utilizados en ambas, con un $42 \%$ y 40\%, respectivamente (Ver gráficos 6 y 7). En estos casos la complementariedad de los dos colores es mayor, por cuanto se utilizan en un mismo titular con el fin de dar equilibrio a la portada.

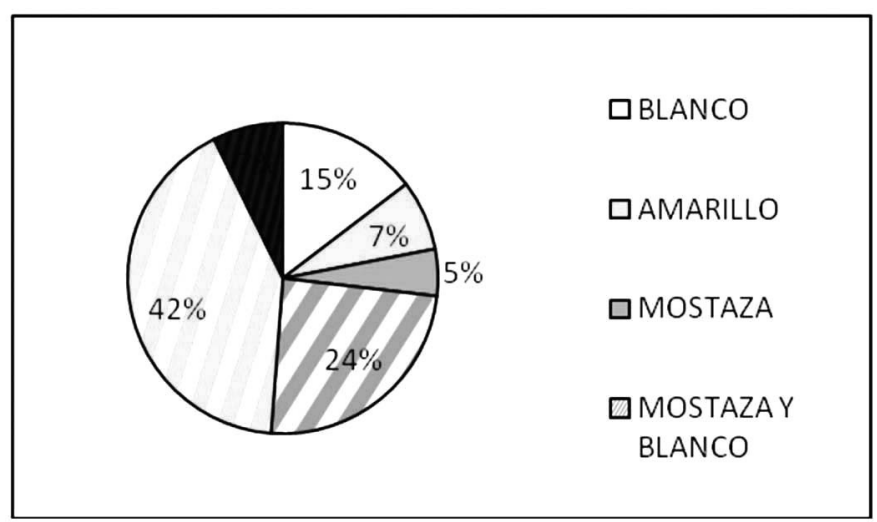

Gráfico 6. Colores de letra en el noticia $\mathrm{N}^{\circ} 3$

Adicionalmente, el uso del blanco como elemento de equilibrio en las noticias $\mathrm{N}^{\circ} 2, \mathrm{~N}^{\circ} 3$ y $\mathrm{N}^{\circ} 4$ (Ver gráficos 5,6 y 7) da una idea sobre el grado de importancia que tienen éstas en la portada. La función de atenuación del color blanco asegura que la noticia $\mathrm{N}^{\circ} 1$ tenga un lugar mucho más sobresaliente dentro de la cubierta frontal de Q'Hubo. Este uso diferenciado del color nos lleva a afirmar que el periódico se identifica y da caracterización a un tipo de noticia específico, guiando la lectura. 


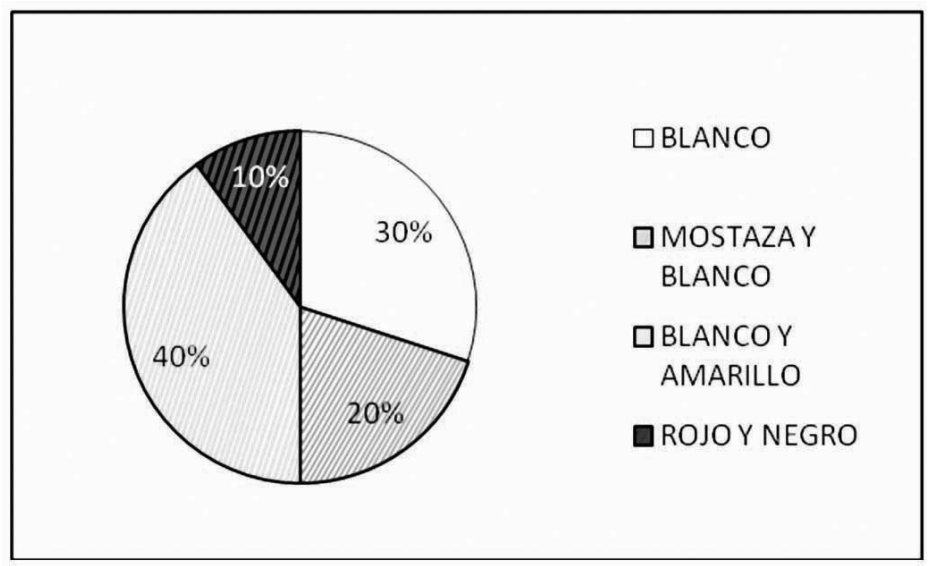

Gráfico 7. Colores de letra en el noticia $\mathrm{N}^{\circ} 4$

\section{Reflexiones finales: Cartagena, ni paraíso ni infierno}

Q'hubo, Al Día y El Teso son los periódicos que realizan el cubrimiento de los hechos de sangre en momentos en que estos han ganado espacio en el mundo cotidiano, en parte por el accionar de las bandas delincuenciales al servicio del narcotráfico. Los tres, nacidos en el lapso de los últimos cinco años - Q'hubo, primero como Nuestro Diario en el 2006, y El Teso y Al Día, a finales del 2010-, compiten por su posicionamiento en el mercado a partir del uso de una estética sensacionalista donde prima, además de una cuidadosa selección de acontecimientos que despiertan el morbo, constantes apelaciones al lenguaje popular y diversas estrategias tipográficas que, en aras de la espectacularización, explotan los significados del tamaño de la letra en los titulares, los colores o la distribución de las imágenes.

Recurriendo a los postulados de la semiótica discursiva, en particular a la Teoría Multimodal, abordamos la estética sensacionalista de $Q$ 'hubo desde las categorías del Valor de la información y la Prominencia, usadas estratégicamente por quienes producen el periódico, para construir un relato atractivo de la violencia homicida, capaz de cautivar la atención de los potenciales lectores: vendedores informales, conductores, desempleados, amas de casa, en fin, de los habitantes populares a los que va dirigido. De esta forma, es claro que los distintos modos semióticos empleados -la gama de colores utilizados en las imágenes y titulares (amarillo, rojo, azul, negro), el tamaño de letra y el estilo específico de titulación -obedecen, no tanto a un fin informativo, sino a una manera de construir el acercamiento con los lectores, en lo que bien puede denominarse la función fática del medio. Esto es así porque los distintos modos de significar que 
confluyen en la portada actúan como marcadores discursivos que determinan y proporcionan caminos o formas de leerla.

El valor de la información se materializa en la asignación de una carga semántica mayor al recuadro informativo que desarrolla la noticia $\mathrm{N}^{\circ}$ 1 , razón por la cual los sucesos asociados con homicidios ocupan un lugar privilegiado en la portada: el centro. Y lo ocupan a través de las imágenes, consideradas como la principal herramienta para captar la atención del lector. Según fuentes del mismo periódico, en $Q^{\prime} h u b o$ siempre se procura conseguir las mejores fotografías (Comunicación personal, marzo 29 de 2011), que no sólo tienen la función de ilustrar un hecho, sino de evidenciarlo justo en primera plana. De esta forma, el análisis de la prominencia reveló que el tamaño de letra utilizado se corresponde con el grado de importancia asignado a una determinada noticia dentro de la portada. Así, se advirtió que para la noticia $\mathrm{N}^{\circ} 1$ el punto de letra oscila entre 100 y 194 puntos, convirtiéndose en un modo semiótico decisivo en el propósito de llamar la atención del lector. El tamaño de letra es, por lo tanto, un claro indicador de los contenidos que el periódico quiere destacar y poner a la vista de todos.

Podemos decir que la forma como está diseñada la portada de $Q$ 'hubo, en tanto conjunto multimodal, no sólo proporciona información sobre un hecho determinado, sino que, además, posibilita una relación más próxima con los lectores, reforzándola con el empleo de un lenguaje coloquial. Por ello los titulares, más allá de brindar información precisa y objetiva sobre un suceso, comunican emociones y juicios sobre el hecho noticioso -de igual forma que en las categorías anteriores, esta estrategia sugiere modos de leer e interpretar la información que aparece en primera plana-. Al estar referida la información a hechos de sangre, el periódico elabora una representación de la ciudad donde el crimen y el delito tienen un lugar privilegiado, hecho que, a nuestro juicio, incide de manera definitiva en la percepción sobre el estado de la seguridad en la ciudad.

Este imaginario que hace de la ciudad un espacio cada vez más peligroso, violento e inseguro, sugiere que el discurso del relato del crimen presentado por la crónica roja ocupa un lugar destacado en la vida de los habitantes de Cartagena y en la generación de sus conocimientos, expectativas y miedos, disputando el dominio ejercido por el discurso turístico en la representación de la ciudad. Y recordando de paso, especialmente a sus habitantes, que Cartagena también es escenario del crimen, del sicariato, de las riñas entre pandillas... Lo paradójico de todo esto es que, al Q'hubo reducir la ciudad a temas violentos (su ubicación en primera plana), del 
mismo modo en que lo hace el discurso turístico, reduce y deforma la representación de la ciudad, ahora asociada casi exclusivamente a contenidos de violencia. Así, lleva a que los lectores se relacionen con la violencia homicida desde el morbo, presuponiendo que este es el tipo de relación que pueden/desean tener.

\section{Bibliografía}

Ávila, F. (2008). La representación de Cartagena en el discurso turístico. Trabajo de grado presentado para optar al Diploma de Estudios Avanzados (DEA) en el Doctorado en Análisis del Discurso y sus Aplicaciones de la Universidad de Salamanca, España.

Blanco Leal, M. (2008) Modelos de análisis para el estudio crítico de la prensa. Ediciones internacionales universitarias. Madrid, España.

Carreras, O. (s.f) "Reseña de libro Psicología del color de Eva Heller", en http://olgacarreras.blogspot.com/2008/11/resea-psicologadel-color-de-eva-heller.html

Ghio, E. \& Fernández, M. D. (2008). Lingüística sistémica funcional: aplicaciones a la lengua española. Santa Fé: Universidad Nacional del Litoral.

Halliday, M. (1982) El Lenguaje como semiótica social: la interpretación social del lenguaje y del significado. México: Fondo de Cultura Económica.

Heller, E. (2004). Psicología del color. España: Gustavo Gili.

Kress, G. R. \& van Leeuwen, T. (2006). Reading images: The grammar of visual design. ( 2 a ed.). Londres: Routledge.

López, O. (2005). Amarilla y roja. Estéticas de la prensa sensacionalista. Medellín: EAFIT.

López, H. (1994). Métodos de investigación lingüística. Salamanca: Ediciones Colegio de España.

Pérez Grajales, H. (2007). Lenguajes verbales y no verbales. Bogotá: Magisterio Editorial.

Rojas, M. (2003). Manual para redactar titulares. México: Trillas.

Vélez, L. F; Giraldo, J. C; Unás, Vivian; Prada, M. A. \& Arango, O. A. (1998). "Crónica roja: hacia un periodismo del abrazo", Chasqui, n ${ }^{\circ}$, en http://www.cisalva.univalle.edu.co/publicaciones/documentos/ cronicaroja.pdf

Zelanski, P. \& Fisher, M. (2001). Color. Barcelona: Blume. 
